\section{NEED ASSESSMENT OF PSYCHOLOGICALLY HURT YOUNG SPINAL INJURED PATIENTS IN NATIONAL INSTITUTE OF TRAUMATOLOGY \& ORTHOPAEDIC REHABILITATION (NITOR), DHAKA}

Sk. Abbas Uddin Ahmed ${ }^{1}$, Abu Saleh Mohammed Monirul Alam $^{2}$, R.R. Kairy ${ }^{3}$

\begin{abstract}
:
Dhaka the capital of Bangladesh is very densely populated. As unemployment increase with every moment, factory owners attract young group to job. So, without training and ability many workers embrace accident, even in crowd situation due to RTA and fall from tree and buildings thus some suffer from spinal injury with or without paraplegia. This paraplegic group of patients are not provided with psychiatric treatment during normal physical treatment due to our unawareness and suffer psychological distress which delay normal usual recovery. Objectives were to explore depth of psychological injury to plan treatment, reassurance and rehabilitation;assess the prevalence of anxiety and depression and change psychological adjustment after initial rehabilitation.This Study was done to find out psychological distress and also to highlight the need of psychological management.The study design was randomized prospective. Data gathered by questionnaire (face to face, telephone and by mail) and indepth interview. The study was conducted from January to December 2004 at paraplegic ward of Tertiary referral Orthopaedic Institute (NITOR), Dhaka.
\end{abstract}

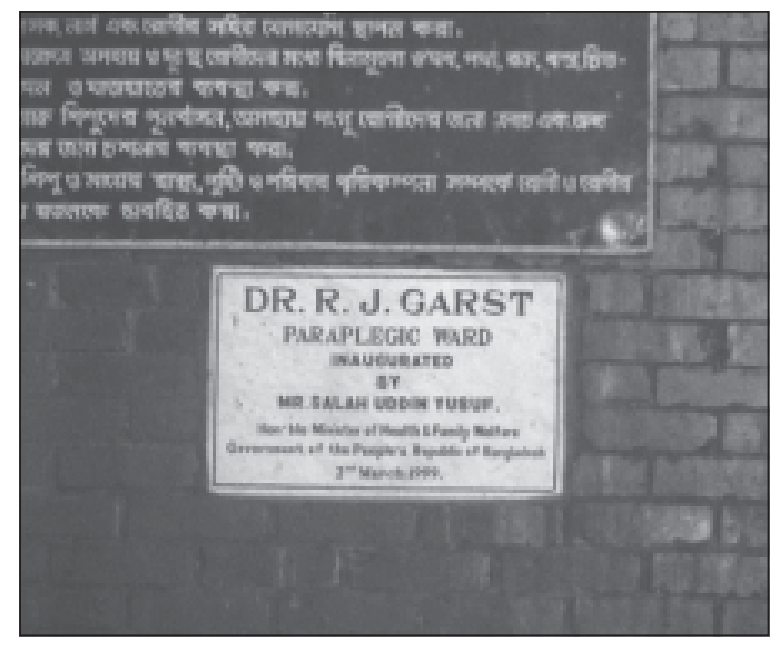

\section{Introduction:}

Non-psychiatric services suffer-undiagnosed psychiatric conditions.Psychiatric disorders in medical or surgical patients$20 \%$ to $80 \%$, (anxiety and depression in various forms are common). ${ }^{1-6}$

Anxiety- subjective feeling of an apprehension, dread or foreboding is accompanied by a wide variety of autonomic signs and symptoms. Prevalence of anxiety disorder in the general population- $2 \%$ to $5 \%$ (higher in woman). $5 \%$ to $20 \%$ medical in-patients and $4 \%$ to $14 \%$ medical out patients have anxiety state. ${ }^{5}$. Depression- Feeling of unhappiness. Depression (Disease process) - Defined as qualitatively and quantitatively distinct from the depression that normally accompanies bereavement or other loss. Prevalence of depression- 3\% to $6 \%$ (male-3\%, female- $4.5 \%$ to $9 \%$ ). ${ }^{4,6,7}$ Kuhn et all (1989)- $46.8 \%$ demonstrated depression.8 Depression- expected psychological reaction of the patient to his disability of restrictions in activity and is a barrier to recovery from orthopaedic problem9.Brief counseling and psychological or 'critical incident' debriefing (PD) following a trauma reduce subsequent morbidity (Mitchell, 1983; Dyregov, 1989). ${ }^{10,11}$. The prevalence of depression in orthopaedic patients is not known in our country, as no study of depression following orthopaedic problem has yet been carried out. 9.Anxiety and depression presentation of symptom intensifies and interfere the physical treatment of the patients due to negative cognition.

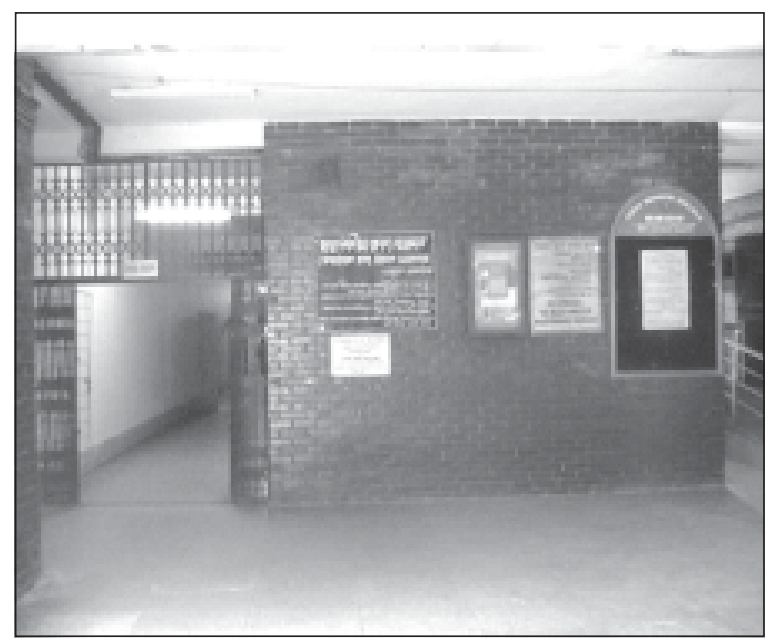

Paraplegic Ward

1. Assistant Professor, National Institute of Traumatology \& Orthopaedic Rehabilitation (NITOR), Dhaka.

2. Registrar, National Institute of Traumatology \& Orthopaedic Rehabilitation (NITOR), Dhaka.

3. Professor, National Institute of Traumatology \& Orthopaedic Rehabilitation (NITOR), Dhaka.

\section{Materials and Methods:}

167 patients were admitted consecutively and out patients with spinal injury. 


\section{Results:}

Age ranging from 15-45 years; 146 (87.43\%) were male and 21 (12.57\%) were female patients. Most of the patients were from primary school level. Complete paraplegic patients- 34.28\% and incomplete paraplegic patients- $65.72 \%$.

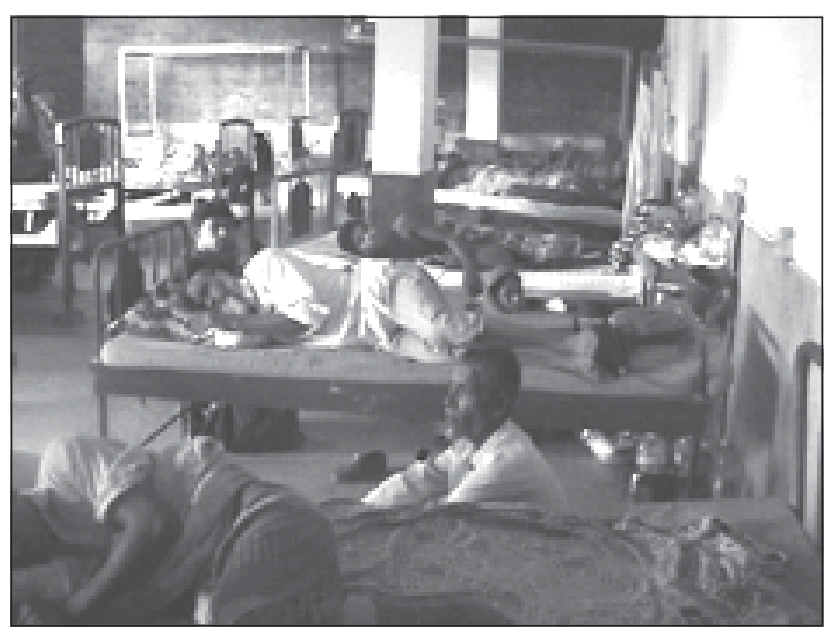

Paraplegic Ward

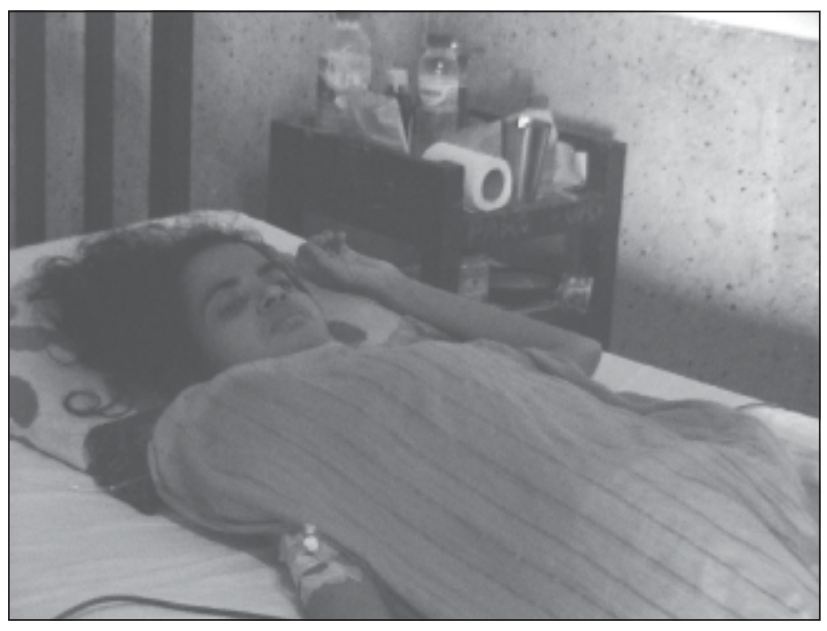

Paraplegic patients

All of them treated conservatively.Hospital stay- 6 weeks (4 weeks to 8 weeks).Follow up-3 monthly, 6 monthly and 12 monthly.Assessment based on ICD-10 criteria for depressive disorder. Mode and level of spine injury shown in table - I \& II.

\section{Table-I}

\begin{tabular}{lc}
\hline Mode of Injury & Number of Patients \\
\hline Falling of heavy weight from head & $59(35.33 \%)$ \\
Falling from tree & $53(31.74 \%)$ \\
Falling from high buildings & $52(19.16 \%)$ \\
Road Traffic Accident & $21(12.57 \%)$ \\
Tuberculosis of spine & $02(01.20 \%)$ \\
\hline
\end{tabular}

Table-II

\begin{tabular}{lc}
\hline Level of Spinal Injury & Number of Patients \\
\hline Cervical Spine & $103(61.68 \%)$ \\
Dorsal Spine & $39(23.35 \%)$ \\
Lumber Spine & $25(14.17 \%)$ \\
\hline
\end{tabular}

Generalized anxiety disorder was assessed by ICD-10 criteria in which the essential feature is anxiety, which is generalized and persistent associated with autonomic symptoms and sings 12.Depressive episode was assessed clinically by ICD-10 criteria for depressive episode 12. ICD-10 criteria for depressive episode is a syndrome that includes a depressive mood and a series of specific somatic and cognitive symptoms of at least 2 weeks is usually required for diagnosis, but shorter periods may be reasonable if symptoms are unusually severe and of rapid onset.

Shown in Table No. III, IV, V.

Table-III: Showing $19.76 \%$ and $80.24 \%$ of the Paraplegic patients were suffering from generalized anxiety and depressive episode respectively.

\begin{tabular}{lcc}
\hline Primary psychiatric diagnosis & Number & Percentage \\
\hline Generalized anxiety disorder & 33 & $19.76 \%$ \\
Depressive episode & 134 & $80.24 \%$ \\
\hline Total Patients : & 167 & \\
\hline
\end{tabular}

Table-IV: Showing the frequency distribution of generalized anxiety symptoms on the basis of ICD-10 criteria. Apprehension, autonomic over activity was present in all the patients with generalized anxiety disorder. Motor tension was found in $69.70 \%$ of the patients.

Table-IV: Shows the frequency distribution of generalized anxiety symptoms on the basis of ICD-10 criteria.

\begin{tabular}{lcc}
\hline Symptoms: & Number & Percentage \\
\hline $\begin{array}{l}\text { Apprehension (Worries about } \\
\text { future misfortune) }\end{array}$ & 33 & $100 \%$ \\
Motor tension (restless, tension & 23 & $69.70 \%$ \\
headache, Trembling inability to relax) & 33 & $100 \%$ \\
Automatic over activity (sweating, & & \\
tachycardia, dry mouth, epigastria & & \\
discomfort) & \\
\hline Total patients : 33 & \\
\hline
\end{tabular}


Table-V: Showing frequency distribution of the Paraplegic patients of depressive episode according to the frequency of symptoms on the basis of ICD-10.

\begin{tabular}{lcc}
\hline Symptom & Number & Percentage \\
\hline Depressed mood & 134 & $100 \%$ \\
Loss of interest and enjoyment & 134 & $100 \%$ \\
Loss of body weight & 134 & $100 \%$ \\
Reduced energy & 134 & $100 \%$ \\
Reduced concentration and attention & 101 & $75 \%$ \\
Ideas of guilt & 67 & $50 \%$ \\
Pessimistic views of the future & 101 & $75 \%$ \\
Disturbed sleep & 67 & $50 \%$ \\
Diminished appetite & 101 & $75 \%$ \\
Reduced self esteem and confidence & 67 & $50 \%$ \\
\hline Total Patients : 134 & & \\
\hline
\end{tabular}

\section{Discussion:}

$5 \%$ to $20 \%$ of medical inpatients and $4 \%$ to $14 \%$ of general medical outpatients suffer anxiety states, with anxiety disorder diagnosed in approximately 6\% of inpatients. Depressive syndrome- $11 \%$ to $26 \%$ of inpatient group (contrasted to $3 \%$ to $6 \%$ of general population). ${ }^{5}$

Positive expectations of rehabilitation- higher educational level. Work situations modifications (job adaptations and reduction of working hours). ${ }^{13}$ Positive expectation regarding resumption of work a Spinal Cord Injury (SCI) are an important indicator of successful reintegration in work, vocational reintegration plan to prepare the patient, the employer and professionals involved in the reintegration process. ${ }^{13}$.In this study paraplegic patients suffering from anxiety disorder $19.71 \%$ and from depressive episode $80.29 \%$.Most of the patients were male (70.69\%). Incomplete paraplegia (65.72) more than complete paraplegia (34.28\%).

Most of them from primary education level and from low socio economic condition. Cervical injury (61.68\%) is more than lumber injury (14.17\%). Mode of injury is mostly due to fall of heavy weight from head during carrying goods overhead. Depression as symptom was found in patients with generalized anxiety disorder. Therefore, depressive features were present in all the paraplegic patients.Generalized anxiety state $27 \%$ and depression 22\% in a study of breast cancer patients. ${ }^{10}$

Moreover, 36 (21.56\%) got 65\% ability of previous job, 131 (78.44\%) suffered from partial ability or total inability to work. So, if all the patients would have got psychiatric management from the beginning and also if they would be mobilized earlier by spinal stabilization then there would be more recovery rate.

\section{Conclusion \& Recommendation :}

In this study none of the depressed paraplegic patients had received psychiatric treatment. This indicates lack of awareness about the existence of depression among the paraplegic patients.Depressed paraplegic patients need psychiatric treatment (counseling to adjust adequately in new situation of life).If the patients were early mobilized by spinal stabilization (Spinal instrumentation)- less psychiatric morbidity and total physical treatment success would be better. So, we need to assess associated psychiatric morbidity of paraplegic patients for psychiatric treatment along with the physical treatment.

\section{References:}

1. Lipowski ZJ. Review of consultation psychiatry and psycho-somatic medicine. Psychosome 1967; XXIX(3): 201-24.

2. Lipowshi ZJ, Wolston EJ. Liaison psychiatry. Referral patterns and their stability overtime. AM J Psychiatry 1981; 138(42): 1608-11.

3. Shevitz SS, Silberfar PM, Lipowski ZJ. Psychiatric consultation in a general hospital. A report on 1000 referrals. Dis Nerve Syst 1967; 37:295-300.

4. Mullick MS. Karim E. Khanam M. Assessment of depression in orthopaedic patients. Journal of Bangladesh Orthopaedic Society 91 and 92: Vol. 6 and 759-63.

5. Wise MG Taylor SE. Anxiety and mood disorders in medically ill patients. J Clin Psychiatry 1990:51;27:32.

6. Thompson C. Mood disorders. Medicine intl 1991;4:39043908.

7. Chowdhury AKMN, Salim M. Sakeb N. Some aspects of psychiatric morbidity in the out patient population a general hospital. Bangladesh Med. Res Counc Bull 1975;:51-59.

8. Kuhn WF, Bell RA, Netscher RE Seligson D and Kuhn SJ. Psychiatric Assessment of Leg Fracture Patients: A Pilot Study. International Journal of Psychiatry in Medicine 1989, 19(2) 145-154.

9. M S I Mullick, E Karim, M Khanam, Ruhul Haque. Assessment of Depression in orthopaedic patients: Journal of Bangladesh Orthopaedic Society, January, 1991 \& 92; Vol-6 \& 7: 59-63.

10. MITCHELL, J.T. (1983) "When disaster strikes.....The critical incident stress debriefing process" Journal of Emergency Medical Services, 8, 36-39.

11. DYREGROV, A. (1989) Caring for helpers in disaster situations: Psychological debriefing. Disaster Management, 2, 25-30.

12. The IDC-10. Classification of Mental and Behavioral Disorder. Clinical Descriptions and diagnostic guidelines. World Health organization, Geneva, 1992.

13. Schonherr M C, Groothoff JW, Mulder G A, Schoppen T, Eisma W.H Vocational reintergration following spinal cord injury: exectations, participation and interventions. 